7. Multicentre Trial Group. Controlled trial of D-penicillamine in severe rheumatoid arthritis. Lancet 1973; $i$ : $275-280$

8. Halberg P. Controlled, double-blind, comparative studies of disease modifying antirheumatic drugs in the treatment of patients with rheumatoid arthritis. Dan Med Bull 1984; $31: 391-482$

9. Schairer H, Stoeber. Long term follow-up of 235 cases of juvenile rheumatoid arthritis treated with D-penicillamine. In : Munthe $E$ ed. Penicillamine research in rheumatoid disease. Oslo : Fabritius and sons 1976 : 279281
10. Ansell BM, Hall MA. Penicillamine in chronic arthritis of childhood. J Rheumatol 1981; 7 (Suppl) : 112-115

11. Prieur AM, Piussan C, Manigne P, Bordigoni, P, Griscelli C. Evaluation of D-penicillamine in juvenile chronic artbritis. Artbritis and Rheumatism 1985; 28 : 376-382

12. Kvien TK, Hyeraal HM, Sandstad B. Slow acting antirheumatic drugs in patients with juvenile rheumatoid arthritis-Evaluation in a randomized, parallel 50-week clinical trial. J Rheumatol 1985; 12 : 533-539

\title{
IMPROVEMENT IN TREATMENT FOR CHLDREN WITH ACUTE LYMPHOBLASTIC LEUKAEMIA
}

Analysis of the results of United Kingdom Acute Lymphoblastic Leukaemia (UKALL) trials since 1972 showed that no improvement in remission or survival had been achieved over the 7 years up to 1979 for 1470 patients in trials UCALL II to VI. UKALL VII (1979-80) gave somewhat better results for a small group of good prognosis patients. However, UKALL VIII, introduced in 1980 produced a $15-20 \%$ increase in 4-year disease-free survival compared with the best results of previous studies, despite a higher frequency of treatment-induced morbidity and mortality. Factors possibly contributing to this highly significant difference include the policy of continuing therapy without interruption during induction, a long course of intramuscular asparaginase over 3 weeks, full-dose mercaptopurine and co-trimoxazole during central-nervous-system prophylaxis, and the use of sustained maximum tolerated oral doses of mercaptopurine and methotrexate maintenance. An intensive sustained approach to chemotherapy in childhood ALL is needed, especially in the early stages of treatment. 